Article

\title{
Antioxidant Potential of Sulfated Polysaccharides from Padina boryana; Protective Effect against Oxidative Stress in In Vitro and In Vivo Zebrafish Model
}

\author{
Thilina U. Jayawardena ${ }^{1,+}$, Lei Wang ${ }^{1,2,+} \mathbb{\infty}$, K. K. Asanka Sanjeewa ${ }^{1} \mathbb{D}$, Sang In Kang ${ }^{3}$, \\ Jung-Suck Lee ${ }^{4, *}$ and You-Jin Jeon ${ }^{1,2, *}$ \\ 1 Department of Marine Life Sciences, Jeju National University, Jeju 690-756, Korea; \\ tuduwaka@gmail.com (T.U.J.); comeonleiwang@163.com (L.W.); asanka.sanjeewa001@gmail.com (K.K.A.S.) \\ 2 Marine Science Institute, Jeju National University, Jeju Self-Governing Province 63333, Korea \\ 3 Department of Seafood and Aquaculture Science, Gyeongsang National University, Tongyeong 53064, Korea; \\ sikang@gnu.ac.kr \\ 4 Research Center for Industrial Development of Seafood, Gyeongsang National University, \\ Tongyeong 53064, Korea \\ * Correspondence: jungsucklee@hanmail.net (J.-S.L.); youjin2014@gmail.com (Y.-J.J.); \\ Tel.: +82-064-754-3475 (Y.-J.J.) \\ + These authors contributed equally to this work.
}

Received: 25 March 2020; Accepted: 13 April 2020; Published: 14 April 2020

\begin{abstract}
Elevated levels of reactive oxygen species (ROS) damage the internal cell components. Padina boryana, a brown alga from the Maldives, was subjected to polysaccharide extraction. The Celluclast enzyme assisted extract (PBE) and ethanol precipitation (PBP) of $P$. boryana were assessed against hydrogen peroxide $\left(\mathrm{H}_{2} \mathrm{O}_{2}\right)$ induced cell damage and zebra fish models. PBP which contains the majority of sulfated polysaccharides based on fucoidan, showed outstanding extracellular ROS scavenging potential against $\mathrm{H}_{2} \mathrm{O}_{2}$. PBP significantly declined the intracellular ROS levels, and exhibited protection against apoptosis. The study revealed PBPs' ability to activate the Nrf2/Keap1 signaling pathway, consequently initiating downstream elements such that catalase (CAT) and superoxide dismutase (SOD). Further, ROS levels, lipid peroxidation values in zebrafish studies were declined with the pre-treatment of PBP. Collectively, the results obtained in the study suggest the polysaccharides from $P$. boryana might be a potent source of water soluble natural antioxidants that could be sustainably utilized in the industrial applications.
\end{abstract}

Keywords: antioxidant; Maldives; Padina boryana; sulfated polysaccharide; zebrafish

\section{Introduction}

Aerobic metabolism results reactive oxygen species (ROS) as its by-product. ROS is comprised of both radical and non-radical species. Distinctively, superoxide anion $\left(\mathrm{O}_{2}^{-\bullet}\right)$, hydroxyl radical $\left({ }^{\bullet} \mathrm{OH}\right)$, and hydrogen peroxide $\left(\mathrm{H}_{2} \mathrm{O}_{2}\right)$ exhibit properties which discuss its involvement in biological targets. ROS possesses two faces; physiological levels support redox biology and pathological levels are explained via oxidative stress. At normal physiological amounts, ROS contributes to the activation of signaling pathways hence initiate biological processes, though oxidative stress damage cellular components including macromolecules such as DNA, lipids, and proteins [1,2]. The effect of ROS elevated levels is counterbalanced with a variety of antioxidants which are divided into two categories namely enzymatic and non-enzymatic. Superoxide dismutase (SOD), catalase (CAT), glutathione peroxidase (GTPx), and glutathione transferase (GST) are foremost components of enzymatic antioxidants. Non-enzymatic 
antioxidants include compounds with a low molecular weight-such as ascorbic acid (vitamin C), $\alpha$-tocopherol (vitamin E), glutathione, and $\beta$-carotene [3]. However, excessive ROS accumulation makes way to countless pathologies such as inflammation, cancer, and abnormal aging. With regard, supplementary antioxidants are beneficial. Such synthetic antioxidants are butylated hydroxytoluene (BHT), and butylated hydroxyanisole (BHA) [4]. However, given its synthetic nature, the human body is vulnerable to side effects. Thus, research endeavors complying with natural antioxidants from sustainable sources have received much attention.

Seaweeds are a source of bioactive components, capable of producing a myriad of secondary metabolites. Previous literature covers antioxidant, anti-fungal, anti-inflammatory, and anti-tumor potential of compounds from vivid algal species. Though seaweeds undergo harsh environmental conditions, such as high intense light and oxygen concentrations, which support the formation of oxidizing components, they manage to prevail without any serious damage. This fact suggests possession of protective compounds and mechanisms among seaweeds $[5,6]$.

Different species of the genus Padina have been subjected to experiments. A range of phytochemicals and their bioactivities were analyzed in Padina tetrastromatica [7]. Padina pavonica was extensively studied for its sulfated hetero-polysaccharides [8,9]. Inhibition of hyaluronidase activity of the Padina pavonica was assessed in its water extract [10].

Polysaccharides are one of the major components of the natural sources available in marine algae. These were reported as effective and non-toxic components with comparatively higher in yield and rather easy to extract, having pharmacological importance [11]. Sulfated polysaccharides inherit distinct attention among other types of polysaccharides due to its numerous bioactivities. Anti-inflammatory [11,12], anti-coagulant [13], anti-proliferative, and antioxidant [14] properties of polysaccharides purified from seaweed species have been studied previously.

This study focuses on the extraction of polysaccharides from brown algae Padina boryana collected from the Maldives. Antioxidant potential of the polysaccharides from P. boryana has not been reported yet, to the best of our knowledge. Hence, the above properties of the polysaccharides are evaluated in vitro (Vero cells) and in vivo (zebrafish) scale.

\section{Results}

\subsection{Chemical Composition}

The celluclast enzyme assisted extract of $P$. boryana (PBE) and ethanol precipitated component PBP were subjected to chemical composition analysis. The results are given in Table 1 . The total phenol content of PBE was $1.32 \pm 0.17 \%$ while PBP exhibited $1.14 \pm 0.26 \%$. Sulfated polysaccharide content was higher in the PBP (56.34\%). Monosaccharide analysis revealed, high contents of fucose and galactose in PBP compared to PBE.

Table 1. Chemical composition of PBE and PBP obtained from P. boryana.

\begin{tabular}{rccc}
\hline \multicolumn{2}{c}{ Sample } & PBE & PBP \\
\hline Polysaccharides content $\%$ & $42.14 \pm 0.86$ & $49.36 \pm 0.79$ \\
\hline Sulfates content $\%$ & $4.57 \pm 0.64$ & $6.98 \pm 0.35$ \\
\hline Phenolic content $\%$ & $1.32 \pm 0.17$ & $1.14 \pm 0.26$ \\
\cline { 2 - 4 } Mono sugars $\%$ & Fucose & 39.84 & 57.51 \\
\cline { 2 - 4 } & Galactose & 15.11 & 21.35 \\
\cline { 2 - 4 } & Mannose & 18.24 & 13.21 \\
\cline { 2 - 4 } & other & 24.81 & 5.63 \\
\hline
\end{tabular}

The analyzed Fourier transform infrared (FTIR) data are illustrated in Figure 1. Glycosidic bonds are formed among multiple monomer units to form polysaccharides and are represented via the 
$1025 \mathrm{~cm}^{-1}$ (C-O-C stretching vibrations) fingerprint peak. An intense peak at the $1200 \mathrm{~cm}^{-1}$ is observed due to the sulfate stretching vibrations $(\mathrm{S}=\mathrm{O})$. While the bending sulfate vibrations are represented via the absorptions at $845 \mathrm{~cm}^{-1}$ (C-O-S). The moisture content available in the sample was observed via the $\mathrm{H}-\mathrm{O}-\mathrm{H}$ bending vibrations in the $1625 \mathrm{~cm}^{-1}$ region $[12,15,16]$. Results suggest the PBP possesses a close correlation with commercial fucoidan.

(a)
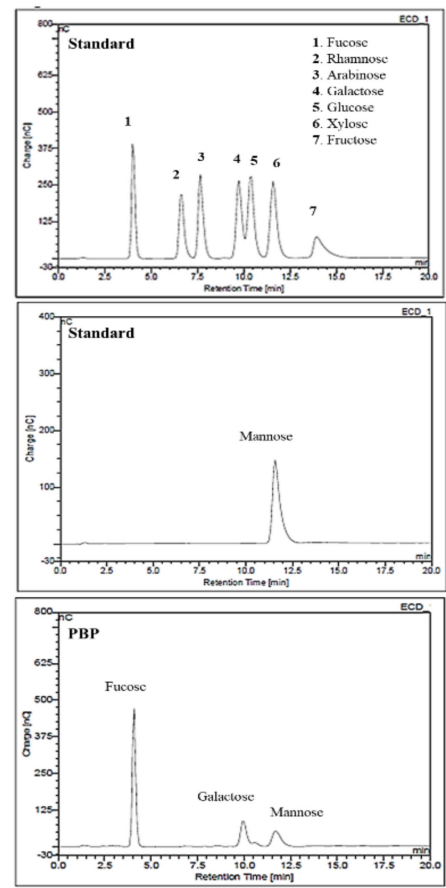

(b)

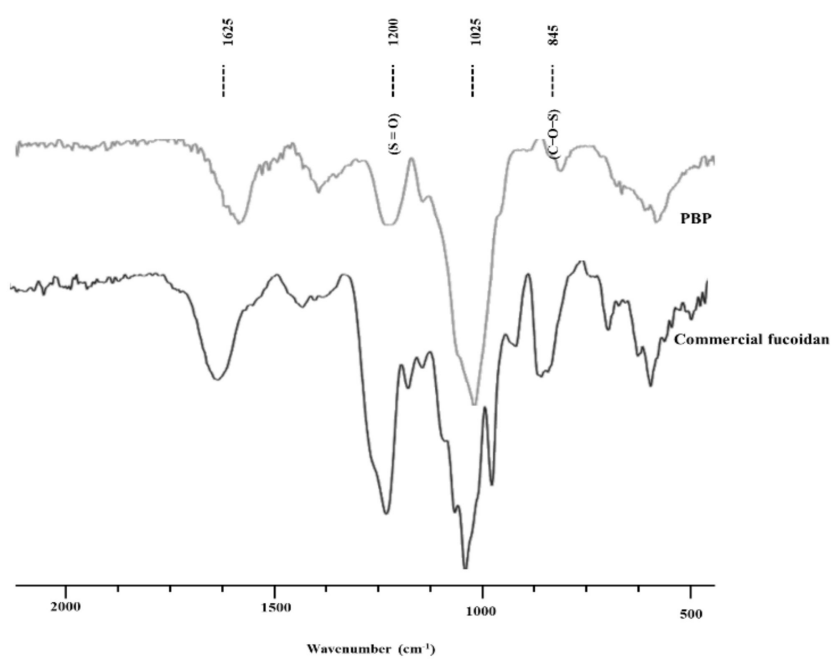

Figure 1. Chemical characterization of PBP. (a) Standard monosaccharide and PBP analyzed by HPAE-PAD spectrum. (b) ATR-FTIR spectra of PBP and commercial fucoidan.

\subsection{Free Radical and Hydrogen Peroxided Scavenging Activity}

The individual radical scavenging activities corresponding to each sample is expressed in Table 2. Both samples exhibited potent scavenging activities where PBP was more active compared to PBE. Interestingly, $\mathrm{H}_{2} \mathrm{O}_{2}$ chemical assay analysis for scavenging also exhibited PBP as the potent, significant scavenger of radicals. Hence, further experiments were planned with the PBP sample.

Table 2. Free radical/ROS scavenging activities of PBE and PBP.

\begin{tabular}{ccccc}
\hline & \multicolumn{4}{c}{ Free Radical/ROS Scavenging Activity $\left(\mathrm{IC}_{\mathbf{5 0}}, \mathbf{m g} / \mathbf{m L}\right)$} \\
\cline { 2 - 5 } & $\mathbf{D P P H}$ & Alkyl & Hydroxyl & $\mathbf{H}_{\mathbf{2}} \mathbf{O}_{\mathbf{2}}$ \\
\hline PBE & $4.26 \pm 0.14$ & $3.88 \pm 0.13$ & $1.96 \pm 0.17$ & $1.17 \pm 0.11$ \\
\hline PBP & $3.66 \pm 0.44$ & $2.87 \pm 0.07$ & $1.06 \pm 0.21$ & $0.58 \pm 0.04$ \\
\hline \multicolumn{5}{c}{ All results expressed as means \pm SE, based on triplicated trials. }
\end{tabular}

\subsection{Protective Effect of PBP in $\mathrm{H}_{2} \mathrm{O}_{2}$ Stimulated Cells}

The PBP exhibited protective effects against the $\mathrm{H}_{2} \mathrm{O}_{2}$ induced cells. The cell viability which was declined with the $\mathrm{H}_{2} \mathrm{O}_{2}$ treatment was reinstated with the PBP treatment. Similarly, the intracellular ROS level which was increased against the $\mathrm{H}_{2} \mathrm{O}_{2}$ stimulation was effectively downregulated with the treatment of PBP. Furthermore, the results exhibited a dose dependent recovery of each indicator (Figure 2). 

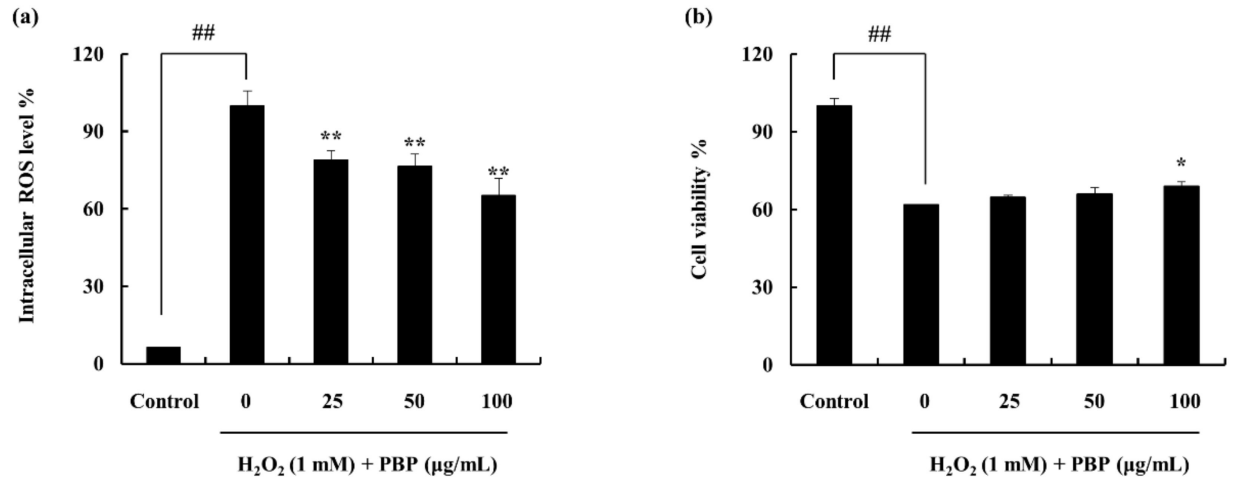

Figure 2. Hydrogen peroxide stimulated Vero cells exhibit oxidative stress. (a) Intracellular reactive oxygen species (ROS) scavenging ability of PBP. (b) PBPs' potential to protect cells against hydrogen peroxide. Experiments were triplicated and data shown as mean $\pm \mathrm{SE}$; $p<0.05$, ${ }^{* *} p<0.01$. (\# denotes significance compared to control while * represents significance compared to $\mathrm{H}_{2} \mathrm{O}_{2}$ treated group).

\subsection{PBP Protects Cells from $\mathrm{H}_{2} \mathrm{O}_{2}$ Induced Apoptosis}

Earlier studies have revealed the effect of $\mathrm{H}_{2} \mathrm{O}_{2}$ on DNA damage leading to apoptosis [17]. Hence, the effect was evaluated through nuclear staining methods. This particular study followed the Hoechst 33342 staining method. Viable cells are indicated via homogeneously stained nuclei while fragmented and chromatin condensed nuclei are an indication of apoptotic cells [18]. As indicated in Figure 3, cells that were exposed to $\mathrm{H}_{2} \mathrm{O}_{2}$ were associated with increased cell death, indicating higher intensity in the nuclei region. The number of apoptotic bodies was significantly decreased with the PBP treatment, which was indicative of its potential to act as a protective substance against ROS.
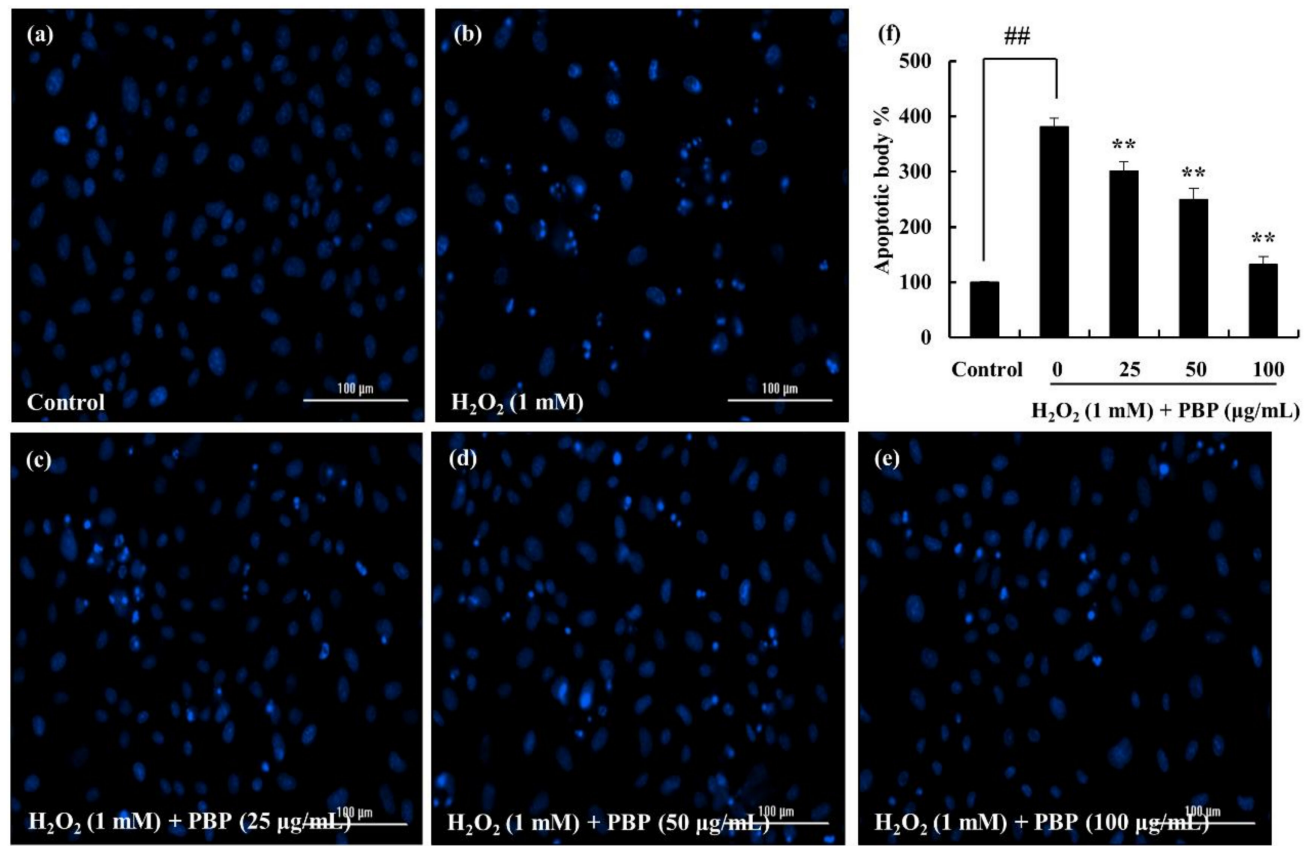

Figure 3. PBP protects Vero cells against $\mathrm{H}_{2} \mathrm{O}_{2}$-induced apoptosis. The apoptotic body formation was observed using Hoechst 33342 staining method under a fluorescence microscope. (a) non-treated group, (b) $\mathrm{H}_{2} \mathrm{O}_{2}$ treated $(1 \mathrm{mM})$ cells, $\mathrm{H}_{2} \mathrm{O}_{2}$ stimulated cells treated with $\mathrm{PBP}$ (c) $25 \mu \mathrm{g} / \mathrm{mL}$, (d) $50 \mu \mathrm{g} / \mathrm{mL}$, (e) $100 \mu \mathrm{g} / \mathrm{mL}$, (f) quantitative representation. The intensity levels were analyzed using ImageJ software. Triplicated experiments were conducted and results are represented as mean $\pm \mathrm{SE} ;{ }^{*} p<0.05,{ }^{* *} p<0.01$. (\# denotes significance compared to control while * represents significance compared to $\mathrm{H}_{2} \mathrm{O}_{2}$ treated group). 


\subsection{Effect of PBP on Antioxidant Enzymes and Pathway Proteins}

CAT and SOD are important enzymes in the process of degrading hydrogen peroxide to protect the cells against oxidative damage. It was observed that the particular enzyme protein levels were significantly declined with the $\mathrm{H}_{2} \mathrm{O}_{2}$ treatment. The co-treatment of the PBP recovered the enzyme levels dose dependently overcoming the effect of $\mathrm{H}_{2} \mathrm{O}_{2}$ (Figure 4a,b). Further, the effect was examined in the Nrf2-Keap1 pathway proteins. The cytoplasm nuclear factor E2-related factor 2 (Nrf2) level was increased while Kelch-like ECH-associated protein 1 (Keap1) exhibited declining intensities. It was observed that PBP encouraged the Nrf2 protein expression and stabilized the Keap1 protein allowing successful translocation of Nrf2 to the nucleus (Figure 4c,d). Collectively, the results obtained suggested the potential of PBP to promote Nrf2 expression and nuclear translocation to induce transcription of antioxidant enzymes such as CAT and SOD.

(a)

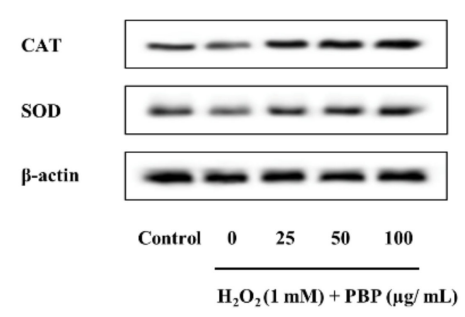

(c)

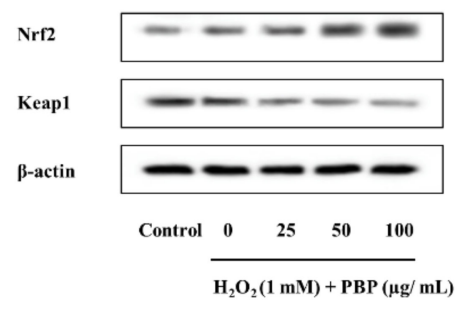

(b)

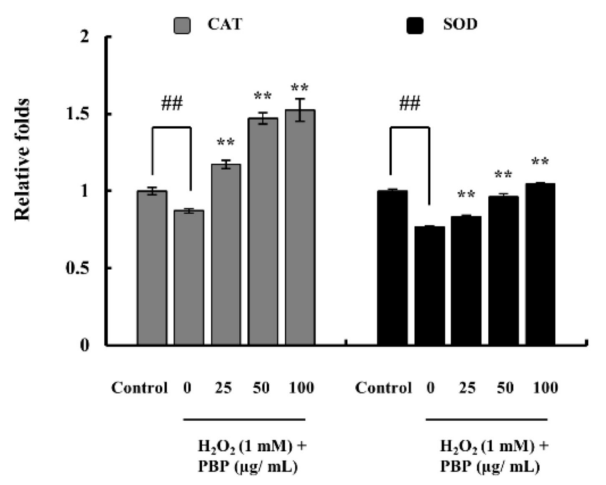

(d)

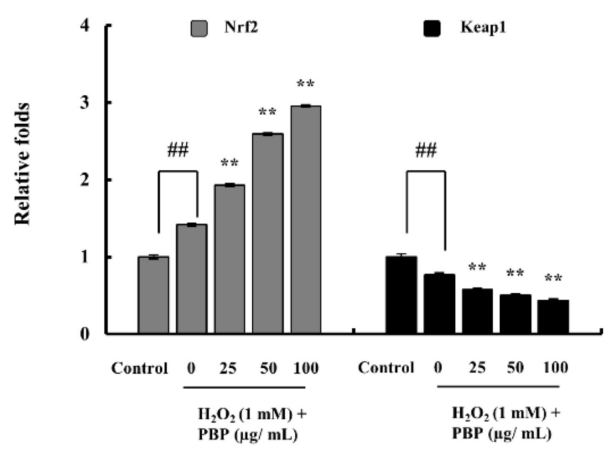

Figure 4. Effect of PBP on the $\mathrm{H}_{2} \mathrm{O}_{2}$ induced antioxidant related protein in Vero cells. (a) CAT and SOD, (b) relevant quantitative data, (c) Nrf2 and Keap1 in cytosol western blot, and (d) relevant quantitative data. $\beta$-actin was used as internal control. Quantification was assisted with the ImageJ software. Results are represented as mean $\pm \mathrm{SE} ;{ }^{*} p<0.05,{ }^{* *} p<0.01$. (\# denotes significance compared to control while * represents significance compared to $\mathrm{H}_{2} \mathrm{O}_{2}$ treated group).

2.6. Potential of PBP to Protect $\mathrm{H}_{2} \mathrm{O}_{2}$ Induced Zebrafish in Lipid Peroxidation, ROS Accumulation, and Cell Death

The survival rate and the heartbeat rate were recorded against the PBP treatment in $\mathrm{H}_{2} \mathrm{O}_{2}$ stimulated zebrafish (Figure 5). The ROS production in the zebrafish embryos treated with $\mathrm{H}_{2} \mathrm{O}_{2}$ was investigated by 2,7-dichlorofluorescein diacetate (DCF-DA). The results are interpreted as an indication of the fluorescence intensity. The $\mathrm{H}_{2} \mathrm{O}_{2}$ treated embryos expressed significantly high fluorescence intensity compared to the non-treated group. PBP pre-treated embryos exhibited a downregulation of fluorescence intensities dose dependently, subduing the effect generated via $\mathrm{H}_{2} \mathrm{O}_{2}$. This reflects the gradual decrement of ROS production, which implies PBPs' ability to work as a protective agent (Figure 6a,b). The amount of lipid peroxidation was measured using the diphenyl-1-pyrenylphosphine (DPPP) staining. Similarly, the results indicated a decline in the amount of lipid peroxidation with 
the PBP treatment, (Figure 6c,d). The cell death which was evaluated through the acridine orange staining exhibited the fluorescent intensities to be declined significantly in $\mathrm{H}_{2} \mathrm{O}_{2}$ induced zebrafish embryos with the PBP treatment (Figure 6e,f). The cell death percentage which was 290 in the $\mathrm{H}_{2} \mathrm{O}_{2}$ treated group was declined up to 170 with the PBP $(100 \mu \mathrm{g} / \mathrm{mL})$ treatment. These results reveal the prospective of $\mathrm{PBP}$ to act as a potent protector against $\mathrm{H}_{2} \mathrm{O}_{2}$ stimulated oxidative stress.

(a)

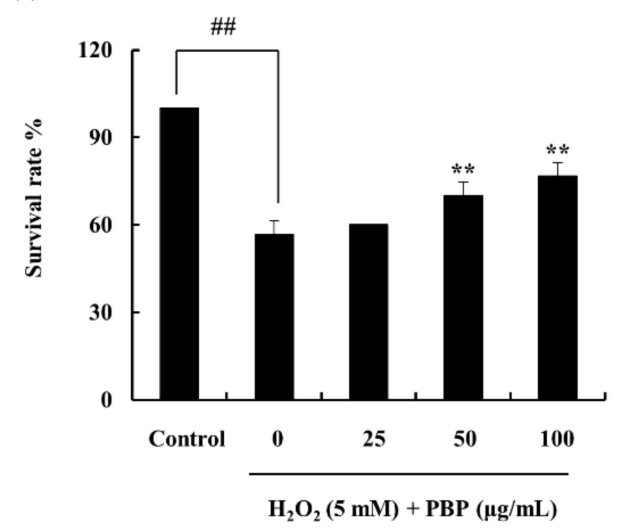

(b)

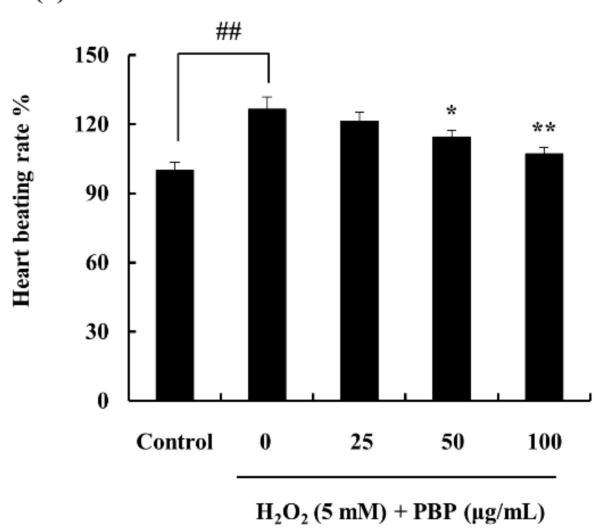

Figure 5. Embryos pre-treated with $\mathrm{H}_{2} \mathrm{O}_{2}(5 \mathrm{mM})$ and followed by PBP treatment $(25,50,100 \mu \mathrm{g} / \mathrm{mL})$. (a) survival rate, and (b) heart beating rate. Experimental procedure followed triplication and data indicated as mean $\pm \mathrm{SE}$; $p<0.05,{ }^{* *} p<0.01$. (\# denotes significance compared to control while * represents significance compared to $\mathrm{H}_{2} \mathrm{O}_{2}$ treated group).

(a)
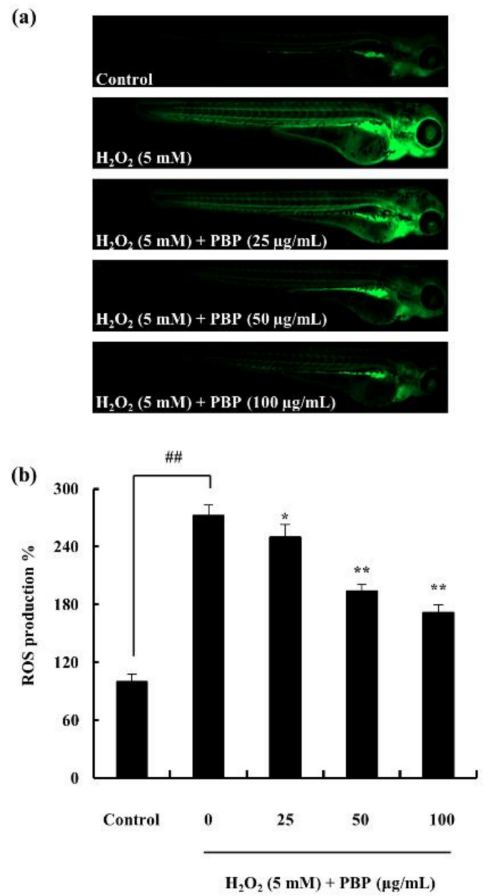

(c)
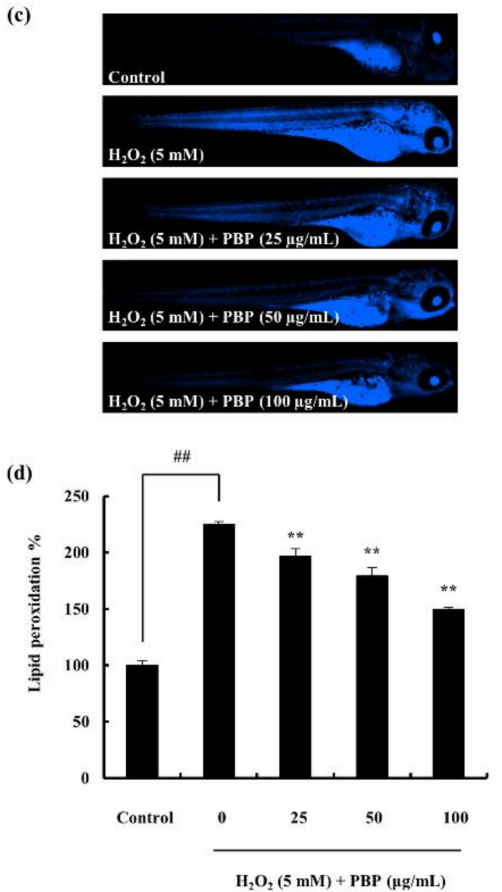

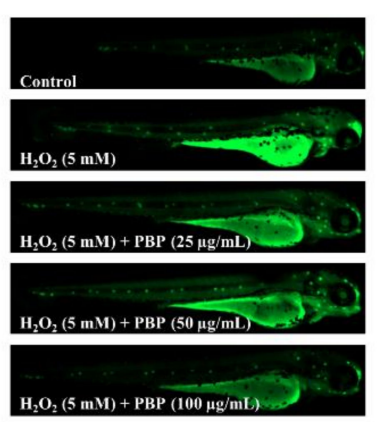

(f)

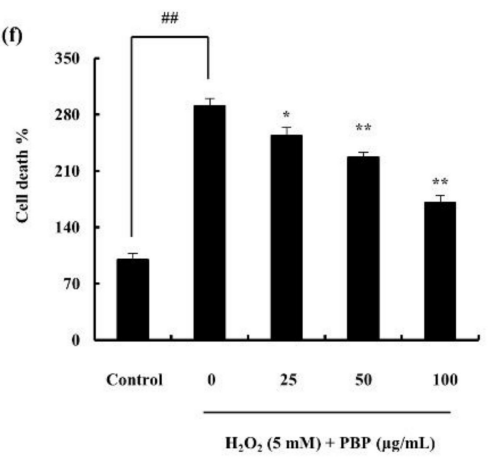

Figure 6. in vivo evaluation of antioxidant potential of PBP. (a) Hydrogen peroxide induced ROS production with DCF-DA staining, (c) Hydrogen peroxide-induced lipid peroxidation production stained with DPPP, (e) PBP protects zebrafish embryos against $\mathrm{H}_{2} \mathrm{O}_{2}$-induced death, stained with acridine orange and captured under fluorescence microscope. Quantitative results of each analysis are represented in (b), (d), and (f) respectively, measured via ImageJ software. Triplicated experiments were conducted and results are represented as mean $\pm \mathrm{SE}$; ${ }^{*} p<0.05,{ }^{* *} p<0.01$. (\# denotes significance compared to control while * represents significance compared to $\mathrm{H}_{2} \mathrm{O}_{2}$ treated group). 


\section{Discussion}

Marine organisms are reported to be immense sources of secondary metabolites that possess novel biological activities. These sources have proven to be useful in the treatment of diseases and hence be utilized prospectively in pharmacology and medicinal sectors [19]. The antioxidant activity of Hawaiian marine algae has been studied by Kelman et al. (2012), providing an extensive report on different marine algal species including red, brown, and green algae [20]. The sulfated polysaccharides from marine algae as a source of antioxidant secondary metabolite were reviewed by Wijesekara et al. (2011) [21]. Brown algae Ecklonia cava was reported as a source of antioxidant components further conducting its abilities in vitro scale. The secondary metabolite of interest; phlorotannin derivatives were reported to be exhibiting noteworthy antioxidant potential [22].

Padina is a genus of brown algae in which the thallus is calcified. The seaweed is fan shaped, widely distributed in warm tropical waters from lower intertidal to deep subtidal zones [23]. Padina boryana, in particular, has previously been studied by Sanjeewa et al. (2019), purifying fucoidan and evaluating its anti-inflammatory properties [24]. The structure of fucoidan was widely evaluated by Usoltseva et al. (2017) [25]. The species form the Maldives has not been deeply studied for its secondary metabolites specifically against antioxidant potentials. Hence, this study aimed to extract water soluble sulfated polysaccharide from the above under-explored brown algae and to investigate its antioxidant properties, specifically on the ethanol precipitation (PBP) which is rich in fucose.

Polysaccharides among other metabolites receive much attention due to their high availability, and diversified structure with vivid functional groups attached to its backbone [26]. Polysaccharides lack structural homogeneity. Fucoidan is one such polysaccharide containing fucose as its main component. Sulfate groups are substituted in the structure of fucose forming ester bonds. Fucoidan is unique due to its higher content of L-fucose and sulfate groups [27]. Different insertions into the backbone of the structure are also possible (mannose, glucose, and galactose). The point of sulfation and the degree of sulfation could be altered form one species to another. The bioactive properties of fucoidans prevail and increase due to the substitution of sulfate groups. One such report emphasized the action of the anionic sulfate group is that it enhances the nonspecific binding of proteins [28]. Hence, the potential of PBP is attributed to the higher degree of polysaccharide content and its sulfate substitution percentage. Another important component of crude polysaccharide is alginate. The chemical composition indicates higher polysaccharide yield in the PBP and sulfate content exhibits a similar trend. The yield of the polysaccharide is justifiable via the activity of celluclast enzyme to breakdown the cell wall. Furthermore, the dielectric constant of the solution is lowered by the addition of ethanol and polysaccharides are precipitated. The structural characterization of the PBP was supported by the FTIR analysis. The FTIR spectral data collectively revealed the correspondence of PBP to commercial fucoidan.

Previous literature reveals the potential of crude polysaccharides to act as antioxidants. The composition including its functional groups and monosaccharides are reported to synergistically induce the free radical scavenging activity $[29,30]$. Therefore, monosaccharide composition of the samples was analyzed and results indicate an increment in fucose and galactose contents. Higher values of fucose and galactose composition were available in PBP compared to PBE accrediting PBPs' elevated potential to act as an antioxidant.

DCF-DA assay was used in the evaluation of intracellular ROS scavenging activities. The stain is absorbed into the cells through the membrane and converted to DCFH, a non-fluorescent component, via the cellular esterases. Thus, intracellular ROS converts DCFH to fluorescent active DCF and detectable with a fluorimeter. Intracellular ROS levels were observed to be upregulated with $\mathrm{H}_{2} \mathrm{O}_{2}$ pre-treatment while treatment with PBP dose-dependently downregulated it. Furthermore, the protective effects of $\mathrm{PBP}$ against $\mathrm{H}_{2} \mathrm{O}_{2}$ were observed by cell viability analysis.

Oxidative stress is caused due to the presence of reactive oxygen species (ROS). Cellular metabolism and environmental factors contribute to the production of ROS. At moderate concentrations, ROS plays an important role in the function of physiological cell processes while high concentrations lead 
to adverse effects [31]. The highly reactive molecules damage cell structures including macromolecules thus alter the physiological functions. Moreover, the imbalance between the ROS and its counterpart antioxidants creates oxidative stress. Cell viability, proliferation rate, and further functions are affected by oxidative stress. Even though aerobic organisms possess integrated antioxidant systems, under pathological conditions these systems can be overwhelmed [3]. $\mathrm{H}_{2} \mathrm{O}_{2}$ is a distinct ROS species with physiological significance among others such as superoxide anion $\left(\mathrm{O}_{2}{ }^{-\bullet}\right)$ and hydroxyl radical $\left({ }^{\bullet} \mathrm{OH}\right) . \mathrm{H}_{2} \mathrm{O}_{2}$ is produced in the cells upon phagocytosis due to the superoxide burst and converted. Xanthine oxidase, $\mathrm{NAD}(\mathrm{P}) \mathrm{H}$ oxidase, and amino acid oxidase contribute in the production of hydrogen peroxide [32]. In the presence of transition metal ions, $\mathrm{H}_{2} \mathrm{O}_{2}$ break down and result in $\mathrm{OH}^{-}$and ${ }^{\bullet} \mathrm{OH}$ via the Fenton reaction [33]. Therefore, this study focuses on the stimulation via $\mathrm{H}_{2} \mathrm{O}_{2}$ under both in vivo and in vitro conditions.

The genetic material is modified by the ROS via different mechanisms involving DNA strand breakage, sugar moiety modifications, base unit degradation, deletions, and translocations [34]. Possible DNA modifications lead to carcinogenesis, aging, and numerous diseases. The effect was evaluated in the study via nuclear staining methods. It was evident the effect of $\mathrm{H}_{2} \mathrm{O}_{2}$ on the condensation and fragmentation of the nuclear material which was dose dependent and down regulated via the treatment of PBP.

Superoxide anion radicals are scavenged via SOD, while CAT plays an important role in the detoxification of the $\mathrm{H}_{2} \mathrm{O}_{2}$. Hence, these could eliminate free radicals and help the conversion of reactive toxic components to non-toxic elements and protect the live organelles from oxidative damage. The antioxidant enzymes were initially hampered by the excess ROS created via the effect of $\mathrm{H}_{2} \mathrm{O}_{2}$, though the potential of PBP recovered the enzyme expression hence reducing ROS production. Keap1 is an inhibitor protein, a cysteine-rich protein that is anchored to the actin cytoskeleton. It is responsible for the cytosolic sequestration of Nrf2 under physiological conditions. Keap1 promotes ubiquitination and degradation of Nrf2 under normal physiological conditions. Under stressful conditions in which the Nrf2-dependent cellular mechanism is active (electrophiles and oxidants are rich in this stage), the Nrf2 is rapidly released from Keap1. Dissociated Nrf2 is translocated to the nucleus and binds to antioxidant response element (ARE). Keap1 also receives redox information or environmental cues via its highly reactive cysteine residues and referred to as the sensor of the Nrf2-Keap1 system [35]. The dissociation of the system is a relatively rapid event. The breakdown of the system leads to Keap1 stabilization. Nrf2 also increases its half-life [36]. This allows successful nuclear translocation and cytoprotective gene transcription. A similar effect of antioxidant polysaccharides was reported by Zhou et al. (2019) [37].

The membrane lipid bilayer is disrupted via ROS stimulated lipid peroxidation thus membrane bound receptor activities are altered leading to increased tissue permeability [38]. Lipid peroxidation results in unsaturated aldehydes which are potent inactivators of cellular proteins through the formation of cross linkages [3]. The effect of ROS was evaluated in vivo scale using zebrafish. The ROS production levels examined via DCFDA fluorescent staining initially indicated the decline of intensities revealing the protective effect of PBP. Furthermore, DPPP staining exhibited the lipid peroxidation intensities to be upregulated under $\mathrm{H}_{2} \mathrm{O}_{2}$ stimulation and significant decline under PBP pre-treatment. The results confirmed the antioxidant potential of PBP against $\mathrm{H}_{2} \mathrm{O}_{2}$ induced oxidative stress. Thus, zebrafish cell death was successfully downregulated dose-dependently as indicated. The results obtained in the study well aligns with an earlier report on polysaccharide extracts from Hizikia fusiforme [39]. Furthermore, fucoidan purified from brown algae has incorporated zebrafish studies as an in vivo model $[12,40]$.

Zebrafish involvement in developmental biology and drug discovery has been recognized and the implementation was advanced throughout the years. The size, husbandry, and early morphology is a distinct advantage of the usage of zebrafish over other vertebrate species. This provides researchers to minimize the costs in maintenance as well as in quantities of dosing samples, further in histological 
assessments [41]. High fertility including transparent embryos makes the species a valuable source [42]. Fluorescent staining methods implemented in the present study also support the above fact.

\section{Material and Methods}

\subsection{Materials}

African monkey kidney cell line (Vero) was purchased from the Korean cell line bank (KCLB, Seoul, Korea). Media for the cell line maintenance (Roswell Park Memorial Institute-1640; RPMI-1640) and serum (fetal bovine serum; FBS) including antibiotics (penicillin, streptomycin) were purchased from Gibco-BRL (Grand Island, NY, USA). 3-(4,5-dimethylthiazol-2-yl)-2,5-diphenyltetrazolium bromide (MTT), 1-diphenyl-2-picrylhydrazyl (DPPH), 2,2-azobis(2-amidinopropane) hydrochloride (AAPH), 5,5-dimethyl-1-pyrolin N-oxide (DMPO), and $\alpha$-(4-Pyridyl-1-oxide)-N-tert-butylnitrone (POBN) were purchased from Sigma (St. Louis, MO, USA). $\mathrm{H}_{2} \mathrm{O}_{2}$ and $\mathrm{FeSO}_{4} .7 \mathrm{H}_{2} \mathrm{O}$ used were purchased from Fluka Co. (Buchs, Switzerland). Furthermore, dimethyl sulfoxide (DMSO), 2,7-dichlorofluorescein diacetate (DCF-DA), and 2,2'-azino-bis(3-ethylbenzthiazoline)-6-sulfonic acid (ABTS) were obtained from Sigma-Aldrich (St. Louis, MO, USA).

\subsection{Collection of Seaweed and Extraction}

P. boryana samples were collected from the shores of Fulhadhoo Island $\left(4.8849^{\circ} \mathrm{N}, 72.9350^{\circ} \mathrm{E}\right)$, the Maldives in January of 2018. Samples were immediately washed with running water to remove epiphytes and sand. Samples were then lyophilized and ground into powder. A sample portion $(50 \mathrm{~g})$ was added to $500 \mathrm{~mL}$ of distilled water. Optimal $\mathrm{pH}$ value was obtained via the addition of $1 \mathrm{M}$ of HCL. Celluclast assisted extraction was carried out in a period of $24 \mathrm{~h}$ under shaking kinetics with optimal conditions $\left(\mathrm{pH} 4.5,50^{\circ} \mathrm{C}\right.$ ). Following the extraction, the enzyme was inactivated via heating the mixture in $100{ }^{\circ} \mathrm{C}$ for $10 \mathrm{~min}$. The filtrate was obtained and $\mathrm{pH}$ was brought back to neutral value. The sample was identified as enzymatic extract of $P$. boryana (PBE).

\subsection{Crude Polysaccharide Preparation}

The above enzymatic extract was mixed with $95 \%$ ethanol (1:3) and was maintained in $4{ }^{\circ} \mathrm{C}$ for $>8 \mathrm{~h}$ period. The precipitate was polysaccharide from P. boryana and was designated as PBP.

\subsection{Chemical Analysis}

The chemical composition of both the PBE and PBP was analyzed using several methods. Official methods of analysis of the Association of Official Analytical Chemists (AOAC) was used to obtain the total polysaccharide content [43]. The polyphenol content was measured accordingly with the method described by Chandler and Dodds (1983) with minor modifications [44]. The sulfate content was evaluated by $\mathrm{BaCl}_{2}$ gelation method [45].

Samples were hydrolyzed in $4 \mathrm{M}$ triflouroacetic acid $\left(4 \mathrm{~h}, 100^{\circ} \mathrm{C}\right)$. This was subjected to CarboPac PA1 cartridge column $(4.5 \times 50 \mathrm{~mm})$ for separation and detected with an ED50 Dionex electrochemical detector (Dionex) concerning monosugar analysis [46].

The attenuated total reflectance Fourier transform infra-red (ATR-FTIR) spectrum was obtained with a Bruker FTIR, Alpha II (Bruker, Karlsruhe, Germany) instrument in the $400-4000 \mathrm{~cm}^{-1}$ wavenumber range. Commercial grade fucoidan was analyzed at the same time.

\subsection{Radical Scavenging Activity Evaluation via Electron Spin Resonance (ESR) Spectrometer}

Both PBE and PBP were analyzed for its radical scavenging activities. DPPH, alkyl, and hydroxyl radical scavenging activities were evaluated using electron spin resonance spectroscopy (ESR, JES-FA200; JEOL, Tokyo, Japan). The DPPH radical scavenging was assessed via the method defined by Nanjo et al. (1996) [47]. The method, in brief, equal volumes of sample and DPPH was mixed vigorously, transferred to a capillary tube and inserted to the ESR spectrometer for measurement. 
Alkyl radical scavenging followed the method described by Hiramoto et al. (1993) [48]. The radical was generated via a reaction mixture of AAPH and 4-POBN with tested sample which was incubated in water bath $\left(37^{\circ} \mathrm{C}, 30 \mathrm{~min}\right)$ and subjected to analysis. The method explained by Finkelstein et al. (1980) was used in the evaluation of the hydroxyl radical scavenging potential [49]. This used the Fenton reaction as the basis and mixed sample in phosphate buffer solution ( $\mathrm{pH} 7.4)$ with equal volumes of $0.3 \mathrm{M}$ DMPO, $10 \mathrm{mM} \mathrm{FeSO}_{4}$, and $10 \mathrm{mM} \mathrm{H}_{2} \mathrm{O}_{2}(200 \mu \mathrm{L})$ for analysis.

\subsection{Chemical Assay for Hydrogen Peroxide}

A colorimetric assay described by Kim et al. (2014) was implemented in the evaluation of the hydrogen peroxide scavenging [50]. The method in brief; each sample was mixed with $0.1 \mathrm{M}$ phosphate buffer ( $\mathrm{pH}$ 5.0, $100 \mu \mathrm{L})$ in a micro well plate. Hydrogen peroxide $(20 \mu \mathrm{L})$ was added and was incubated $\left(37^{\circ} \mathrm{C}, 5 \mathrm{~min}\right)$. ABTS $(1.25 \mathrm{mM}, 30 \mu \mathrm{L})$ and peroxidase $(1 \mathrm{unit} / \mathrm{mL}, 30 \mu \mathrm{L})$ was added to the above and further incubated at $37^{\circ} \mathrm{C}$ for $10 \mathrm{~min}$. The absorbance measurements were collected using an ELISA reader at $405 \mathrm{~nm}$.

\subsection{Protective Effects of PBP via In Vitro Methods}

\subsubsection{Cell Culture}

RPMI-1640 medium supplemented with heat-inactivated FBS and antibiotics (penicillin and streptomycin) was used to culture the Vero cells. The cells were maintained in controlled environment (humidified, $5 \% \mathrm{CO}_{2}$ ). Periodic subculture was continued and cells were subjected to experiments at its exponential growth phase.

\subsubsection{Cell Viability and Intracellular ROS Scavenging Activity in $\mathrm{H}_{2} \mathrm{O}_{2}$ Stimulated Vero Cells}

Cells were seeded $\left(1 \times 10^{5}\right.$ cells $\left./ \mathrm{mL}\right)$ and were incubated for $16 \mathrm{~h}$, samples were treated and incubated for $1 \mathrm{~h}$. Following the cells were stimulated with $\mathrm{H}_{2} \mathrm{O}_{2}(1 \mathrm{mM})$. The cell viability was measured given $24 \mathrm{~h}$ incubation time using the MTT assay [51]. The intracellular ROS scavenging potential of the samples was measured using the dichloro- fluorescein diacetate (DCF-DA) assay [52]. Initially, the cells were seeded $\left(1 \times 10^{5}\right.$ cells $\left./ \mathrm{mL}\right)$, incubated and treated with different sample concentrations. Cells were stimulated with $\mathrm{H}_{2} \mathrm{O}_{2}$ given $1 \mathrm{~h}$ incubation time and DCF-DA $(500 \mu \mathrm{g} / \mathrm{mL}$, stock) was treated to each well. The results were detected as a fluorescence measurement (Ex- $485 \mathrm{~nm}$, Em-530 nm) with a microplate reader (BioTech, Winooski, VT, USA).

\subsection{3. $\mathrm{H}_{2} \mathrm{O}_{2}$ Induced Cell Apoptosis through Nuclear Staining}

The cells were seeded as explained above, treated with samples and was induced with $\mathrm{H}_{2} \mathrm{O}_{2}$. Following a $24 \mathrm{~h}$ incubation period, the cells were stained with cell permeable DNA dye Hoechst 33342 $(10 \mu \mathrm{g} / \mathrm{mL})$. Given $10 \mathrm{~min}$ incubation period, the cells were observed by a fluorescence microscope equipped with a CoolSNAP-Pro color digital camera (Olympus, Tokyo, Japan) [53,54].

\subsubsection{Western Blot Analysis}

Protein expression levels of catalase (CAT), superoxide dismutase (SOD), nuclear factor E2-related factor 2 (Nrf2), and Kelch-like ECH-associated protein 1 (Keap1) were analyzed via western blotting. Cells were seeded in 6 well culture plates and samples were treated given $24 \mathrm{~h}$ period, following $1 \mathrm{~h}$ incubation cells were stimulated with $\mathrm{H}_{2} \mathrm{O}_{2}$. Cells were harvested after complete incubation and lysed. Protein content was measured and standardized. Following electrophoresis, it was transferred on to nitrocellulose membranes. Blocked membranes (5\% skim milk) were incubated with primary and secondary antibodies step wisely (Santa Cruz Biotechnology, Paso Robles, CA, USA). The bands were developed and photographed via a FUSION SOLO Vilber Lourmat system. ImageJ program was assisted in the quantification of the band intensities [55,56]. 


\subsection{In Vivo Antioxidant Effects of PBP Using Zebrafish Model}

\subsubsection{Zebrafish Maintenance}

Zebrafish in their adult stage were purchased from Seoul Aquarium, Korea. The fish were maintained in acrylic tanks under controlled conditions $\left(28.5^{\circ} \mathrm{C}\right.$, with a $14 / 10 \mathrm{~h}$ light/dark cycle). Fish were fed with tetramin flake, including live brine shrimp, three times per day in equal intervals for 6 days of the week. Natural spawning was stimulated with lights on conditions to obtain the embryos and completed collection within $30 \mathrm{~min}$.

\subsubsection{Polysaccharide Application to Zebrafish Embryos}

The embryos were transferred to 12 well plates after 7-9 h post-fertilization (hpf). The embryos were maintained in an embryo medium. Samples were treated and incubated for $1 \mathrm{~h}$ and stimulated with $\mathrm{H}_{2} \mathrm{O}_{2}(5 \mathrm{mM})$ and continued incubation for $24 \mathrm{hpf}$. The live embryos were counted after 3 days of post-fertilization (dpf) to obtain the survival rate.

\subsubsection{Intracellular ROS, Lipid Peroxidation, and Viability Analysis}

At 2 days of post fertilization (dpf), the heartbeat rate was evaluated. Both the atrium and ventricle heartbeat rate was assessed under microscope for $1 \mathrm{~min}$. The zebrafish were initially treated with sample and was induced with $\mathrm{H}_{2} \mathrm{O}_{2}$ [57].

DCF-DA was used to detect the intracellular ROS levels in the zebrafish embryos while lipid peroxidation was assessed via DPPP. Moreover, cell death was evaluated with acridine orange staining. Following each staining method, the embryos, zebrafish larvae were rinsed with embryo media and anaesthetized with 2-phenox ethanol. A microscope equipped with CoolSNAP-Pro color digital camera (Olympus, Tokyo, Japan) was assisted in observation and photography. The intensity quantification was completed with the ImageJ program [58].

\subsection{Statistical Analysis}

The experiments were triplicated and expressed data as the mean \pm standard error (SE). One-way ANOVA was implemented in the comparison of mean values. Significance among the treatments were evaluated by Student's $t$-test $(p<0.05, p<0.01)$.

\section{Conclusions}

This study evaluated sulfated polysaccharide from marine brown alga P. boryana ethanol precipitation (PBP) as a source of natural antioxidants. Preliminary chemical characterization revealed its composition and the contribution of sulfate content, fucose, and galactose towards the bioactive properties. Results suggest the ability of PBP to protect ROS mediated cell damage and to inhibit oxidative stress in zebrafish. The increased antioxidant pathway protein expression of Nrf2 and its resulting CAT, SOD protein levels accompanied the effect of PBP. Hence, PBP is a potential source of antioxidants that could be successfully utilized in healthy functional and cosmeceutical sectors.

Author Contributions: Conceived and designed the experiments: Y.-J.J.; Performed the experiments: L.W., T.U.J.; Analyzed data: L.W., T.U.J.; Contributed reagents/materials/analysis tools: K.K.A.S., S.I.K., J.-S.L.; Wrote the paper: T.U.J. All authors have read and agreed to the published version of the manuscript.

Funding: This research was financially supported by a grant from the "Marine Biotechnology program-20170488", funded by the Ministry of Oceans and Fisheries, Korea.

Acknowledgments: This research was financially supported by a grant from the "Marine Biotechnology program-20170488", funded by the Ministry of Oceans and Fisheries, Korea.

Conflicts of Interest: The authors declare to possess no competing interests. 


\section{References}

1. Schieber, M.; Chandel, N.S. ROS function in redox signaling and oxidative stress. Curr. Biol. 2014, 24, R453-R462. [CrossRef]

2. Finkel, T. Signal transduction by reactive oxygen species. J. Cell Biol. 2011, 194, 7-15. [CrossRef] [PubMed]

3. Birben, E.; Sahiner, U.M.; Sackesen, C.; Erzurum, S.; Kalayci, O. Oxidative stress and antioxidant defense. World Allergy Organ. J. 2012, 5, 9-19. [CrossRef] [PubMed]

4. Kang, M.C.; Kim, S.Y.; Kim, Y.T.; Kim, E.A.; Lee, S.H.; Ko, S.C.; Wijesinghe, W.A.; Samarakoon, K.W.; Kim, Y.S.; Cho, J.H.; et al. In vitro and in vivo antioxidant activities of polysaccharide purified from aloe vera (Aloe barbadensis) gel. Carbohydr. Polym. 2014, 99, 365-371. [CrossRef] [PubMed]

5. Chew, Y.L.; Lim, Y.Y.; Omar, M.; Khoo, K.S. Antioxidant activity of three edible seaweeds from two areas in South East Asia. LWT - Food Sci. Technol. 2008, 41, 1067-1072. [CrossRef]

6. Chanda, S.; Dave, R.; Kaneria, M.; Nagani, K. Seaweeds: A novel, untapped source of drugs from sea to combat infectious diseases. Curr. Res. Technol. Educ. Top. Appl. Microbiol. Microb. Biotech. 2010, 1, 473-480.

7. Ponnanikajamideen, M.; Malini, M.; Malarkodi, C.; Rajeshkumar, S. Bioactivity and phytochemical constituents of marine brown seaweed (Padina tetrastromatica) extract from various organic solvents. Int. J. Pharm. Ther. 2014, 5, 108-112.

8. Magdel-Din Hussein, M.; Abdel-Aziz, A.; Mohamed Salem, H. Some structural features of a new sulphated heteropolysaccharide from Padina pavonia. Phytochemistry 1980, 19, 2133-2135. [CrossRef]

9. Magdel-Din Hussein, M.; Abdel-Aziz, A.; Mohamed Salem, H. Sulphated heteropolysaccharides from Padina pavonia. Phytochemistry 1980, 19, 2131-2132. [CrossRef]

10. Fayad, S.; Nehme, R.; Tannoury, M.; Lesellier, E.; Pichon, C.; Morin, P. Macroalga Padina pavonica water extracts obtained by pressurized liquid extraction and microwave-assisted extraction inhibit hyaluronidase activity as shown by capillary electrophoresis. J. Chromatogr. A 2017, 1497, 19-27. [CrossRef]

11. Ananthi, S.; Raghavendran, H.R.; Sunil, A.G.; Gayathri, V.; Ramakrishnan, G.; Vasanthi, H.R. In vitro antioxidant and in vivo anti-inflammatory potential of crude polysaccharide from Turbinaria ornata (Marine Brown Alga). Food Chem. Toxicol. 2010, 48, 187-192. [CrossRef] [PubMed]

12. Jayawardena, T.U.; Fernando, I.P.S.; Lee, W.W.; Sanjeewa, K.K.A.; Kim, H.S.; Lee, D.S.; Jeon, Y.J. Isolation and purification of fucoidan fraction in Turbinaria ornata from the Maldives; Inflammation inhibitory potential under LPS stimulated conditions in in-vitro and in-vivo models. Int. J. Biol. Macromol. 2019, 131, 614-623. [CrossRef] [PubMed]

13. Athukorala, Y.; Lee, K.W.; Kim, S.K.; Jeon, Y.J. Anticoagulant activity of marine green and brown algae collected from Jeju Island in Korea. Bioresour. Technol. 2007, 98, 1711-1716. [CrossRef] [PubMed]

14. Athukorala, Y.; Kim, K.N.; Jeon, Y.J. Antiproliferative and antioxidant properties of an enzymatic hydrolysate from brown alga, Ecklonia cava. Food Chem. Toxicol. 2006, 44, 1065-1074. [CrossRef]

15. Marais, M.F.; Joseleau, J.P. A fucoidan fraction from Ascophyllum nodosum. Carbohydr. Res. 2001, 336, 155-159. [CrossRef]

16. Lim, S.J.; Wan Aida, W.M.; Maskat, M.Y.; Mamot, S.; Ropien, J.; Mazita Mohd, D. Isolation and antioxidant capacity of fucoidan from selected Malaysian seaweeds. Food Hydrocoll. 2014, 42, 280-288. [CrossRef]

17. Hemnani, T.; Parihar, M.S. Reactive oxygen species and oxidative DNA damage. Indian J. Physiol. Pharmacol. 1998, 42, 440-452.

18. Ahn, G.; Lee, W.; Kim, K.N.; Lee, J.H.; Heo, S.J.; Kang, N.; Lee, S.H.; Ahn, C.B.; Jeon, Y.J. A sulfated polysaccharide of Ecklonia cava inhibits the growth of colon cancer cells by inducing apoptosis. EXCLI J. 2015, 14, 294-306.

19. Takamatsu, S.; Hodges, T.W.; Rajbhandari, I.; Gerwick, W.H.; Hamann, M.T.; Nagle, D.G. Marine natural products as novel antioxidant prototypes. J. Nat. Prod. 2003, 66, 605-608. [CrossRef]

20. Kelman, D.; Posner, E.K.; McDermid, K.J.; Tabandera, N.K.; Wright, P.R.; Wright, A.D. Antioxidant activity of Hawaiian marine algae. Mar. Drugs 2012, 10, 403-416. [CrossRef]

21. Wijesekara, I.; Pangestuti, R.; Kim, S.-K. Biological activities and potential health benefits of sulfated polysaccharides derived from marine algae. Carbohydr. Polym. 2011, 84, 14-21. [CrossRef]

22. Li, Y.; Qian, Z.J.; Ryu, B.; Lee, S.H.; Kim, M.M.; Kim, S.K. Chemical components and its antioxidant properties in vitro: An edible marine brown alga, Ecklonia cava. Bioorg. Med. Chem. 2009, 17, 1963-1973. [CrossRef] [PubMed] 
23. Win, N.N.; Hanyuda, T.; Arai, S.; Uchimura, M.; Prathep, A.; Draisma, S.G.; Phang, S.M.; Abbott, I.A.; Millar, A.J.; Kawai, H. A Taxonomic Study of the Genus Padina (Dictyotales, Phaeophyceae) Including the Descriptions of Four New Species from Japan, Hawaii, and the Andaman Sea(1). J. Phycol. 2011, 47, 1193-1209. [CrossRef] [PubMed]

24. Asanka Sanjeewa, K.K.; Jayawardena, T.U.; Kim, H.S.; Kim, S.Y.; Shanura Fernando, I.P.; Wang, L.; Abetunga, D.T.U.; Kim, W.S.; Lee, D.S.; Jeon, Y.J. Fucoidan isolated from Padina commersonii inhibit LPS-induced inflammation in macrophages blocking TLR/NF-kappaB signal pathway. Carbohydr. Polym. 2019, 224, 115195. [CrossRef]

25. Usoltseva, R.V.; Anastyuk, S.D.; Ishina, I.A.; Isakov, V.V.; Zvyagintseva, T.N.; Thinh, P.D.; Zadorozhny, P.A.; Dmitrenok, P.S.; Ermakova, S.P. Structural characteristics and anticancer activity in vitro of fucoidan from brown alga Padina boryana. Carbohydr. Polym. 2018, 184, 260-268. [CrossRef]

26. Fernando, I.P.S.; Sanjeewa, K.K.A.; Samarakoon, K.W.; Lee, W.W.; Kim, H.-S.; Kim, E.-A.; Gunasekara, U.K.D.S.S.; Abeytunga, D.T.U.; Nanayakkara, C.; De Silva, E.D.; et al. FTIR characterization and antioxidant activity of water soluble crude polysaccharides of Sri Lankan marine algae. Algae 2017, 32, 75-86. [CrossRef]

27. Li, B.; Lu, F.; Wei, X.; Zhao, R. Fucoidan: Structure and bioactivity. Molecules 2008, 13, 1671-1695. [CrossRef]

28. Mulloy, B. The specificity of interactions between proteins and sulfated polysaccharides. An. Acad. Bras. Cienc. 2005, 77, 651-664. [CrossRef]

29. Chen, Y.; Xie, M.-Y.; Nie, S.-P.; Li, C.; Wang, Y.-X. Purification, composition analysis and antioxidant activity of a polysaccharide from the fruiting bodies of Ganoderma atrum. Food Chem. 2008, 107, 231-241. [CrossRef]

30. Lo, T.C.-T.; Chang, C.A.; Chiu, K.-H.; Tsay, P.-K.; Jen, J.-F. Correlation evaluation of antioxidant properties on the monosaccharide components and glycosyl linkages of polysaccharide with different measuring methods. Carbohydr. Polym. 2011, 86, 320-327. [CrossRef]

31. Valko, M.; Rhodes, C.J.; Moncol, J.; Izakovic, M.; Mazur, M. Free radicals, metals and antioxidants in oxidative stress-induced cancer. Chem. Biol. Interact. 2006, 160, 1-40. [CrossRef] [PubMed]

32. Dupuy, C.; Virion, A.; Ohayon, R.; Kaniewski, J.; Deme, D.; Pommier, J. Mechanism of hydrogen peroxide formation catalyzed by NADPH oxidase in thyroid plasma membrane. J. Biol. Chem. 1991, 266, 3739-3743. [PubMed]

33. Winterbourn, C.C. Toxicity of iron and hydrogen peroxide: The Fenton reaction. Toxicol. Lett. 1995, 82-83, 969-974. [CrossRef]

34. Sallmyr, A.; Fan, J.; Rassool, F.V. Genomic instability in myeloid malignancies: Increased reactive oxygen species (ROS), DNA double strand breaks (DSBs) and error-prone repair. Cancer Lett. 2008, 270, 1-9. [CrossRef] [PubMed]

35. Loboda, A.; Damulewicz, M.; Pyza, E.; Jozkowicz, A.; Dulak, J. Role of Nrf2/HO-1 system in development, oxidative stress response and diseases: An evolutionarily conserved mechanism. Cell Mol. Life Sci. 2016, 73, 3221-3247. [CrossRef] [PubMed]

36. Canning, P.; Sorrell, F.J.; Bullock, A.N. Structural basis of Keap1 interactions with Nrf2. Free Radic. Biol. Med. 2015, 88, 101-107. [CrossRef]

37. Zhou, T.Y.; Xiang, X.W.; Du, M.; Zhang, L.F.; Cheng, N.X.; Liu, X.L.; Zheng, B.; Wen, Z.S. Protective effect of polysaccharides of sea cucumber Acaudina leucoprocta on hydrogen peroxide-induced oxidative injury in RAW264.7 cells. Int. J. Biol. Macromol. 2019, 139, 1133-1140. [CrossRef]

38. Dhindsa, R.S.; Plumb-Dhindsa, P.; Thorpe, T.A. Leaf Senescence: Correlated with Increased Levels of Membrane Permeability and Lipid Peroxidation, and Decreased Levels of Superoxide Dismutase and Catalase. J. Exp. Bot. 1981, 32, 93-101. [CrossRef]

39. Wang, L.; Oh, J.Y.; Kim, H.S.; Lee, W.; Cui, Y.; Lee, H.G.; Kim, Y.-T.; Ko, J.Y.; Jeon, Y.-J. Protective effect of polysaccharides from Celluclast-assisted extract of Hizikia fusiforme against hydrogen peroxide-induced oxidative stress in vitro in Vero cells and in vivo in zebrafish. Int. J. Biol. Macromol. 2018, 112, 483-489. [CrossRef]

40. Fernando, I.P.S.; Sanjeewa, K.K.A.; Samarakoon, K.W.; Lee, W.W.; Kim, H.-S.; Kang, N.; Ranasinghe, P.; Lee, H.-S.; Jeon, Y.-J. A fucoidan fraction purified from Chnoospora minima: A potential inhibitor of LPS-induced inflammatory responses. Int. J. Biol. Macromol. 2017, 104, 1185-1193. [CrossRef]

41. Hill, A.J.; Howard, C.V.; Cossins, A.R. Efficient embedding technique for preparing small specimens for stereological volume estimation: Zebrafish larvae. J. Microsc. 2002, 206, 179-181. [CrossRef] [PubMed] 
42. Hill, A.J.; Teraoka, H.; Heideman, W.; Peterson, R.E. Zebrafish as a model vertebrate for investigating chemical toxicity. Toxicol. Sci. 2005, 86, 6-19. [CrossRef] [PubMed]

43. Cunniff, P. Official methods of analysis of the Association of Official Analytical Chemists International. Arlingt. AOAC Int. 1995, 11, 6-7.

44. Chandler, S.F.; Dodds, J.H. The effect of phosphate, nitrogen and sucrose on the production of phenolics and solasodine in callus cultures of solanum laciniatum. Plant. Cell. Rep. 1983, 2, 205-208. [CrossRef]

45. Dodgson, K.S.; Price, R.G. A note on the determination of the ester sulphate content of sulphated polysaccharides. Biochem. J. 1962, 84, 106-110. [CrossRef]

46. Sanjeewa, K.K.A.; Fernando, I.P.S.; Kim, S.Y.; Kim, H.S.; Ahn, G.; Jee, Y.; Jeon, Y.J. In vitro and in vivo anti-inflammatory activities of high molecular weight sulfated polysaccharide; containing fucose separated from Sargassum horneri: Short communication. Int. J. Biol. Macromol. 2018, 107, 803-807. [CrossRef]

47. Nanjo, F.; Goto, K.; Seto, R.; Suzuki, M.; Sakai, M.; Hara, Y. Scavenging effects of tea catechins and their derivatives on 1,1-diphenyl-2-picrylhydrazyl radical. Free Radic. Res. Commun. 1996, 21, 895-902. [CrossRef]

48. Hiramoto, K.; Johkoh, H.; Sako, K.; Kikugawa, K. DNA breaking activity of the carbon-centered radical generated from 2,2'-azobis(2-amidinopropane) hydrochloride (AAPH). Free Radic. Res. Commun. 1993, 19, 323-332. [CrossRef]

49. Finkelstein, E.; Rosen, G.M.; Rauckman, E.J. Spin trapping of superoxide and hydroxyl radical: Practical aspects. Arch. Biochem. Biophys. 1980, 200,1-16. [CrossRef]

50. Kim, H.-S.; Zhang, C.; Lee, J.-H.; Ko, J.-Y.; Kim, E.-A.; Kang, N.; Jeon, Y.-J. Evaluation of the Biological Activities of Marine Bacteria Collected from Jeju Island, Korea, and Isolation of Active Compounds from their Secondary Metabolites. Fish. Aquat. Sci. 2014, 17, 215-222. [CrossRef]

51. Samarakoon, K.W.; Ko, J.-Y.; Shah, M.M.R.; Lee, J.-H.; Kang, M.-C.; Kwon, O.N.; Lee, J.-B.; Jeon, Y.-J. In vitro studies of anti-inflammatory and anticancer activities of organic solvent extracts from cultured marine microalgae. Algae 2013, 28, 111-119. [CrossRef]

52. Yang, X.; Kang, M.-C.; Lee, K.-W.; Kang, S.-M.; Lee, W.-W.; Jeon, Y.-J. Antioxidant activity and cell protective effect of loliolide isolated from Sargassum ringgoldianum subsp. coreanum. Algae 2011, 26, 201-208. [CrossRef]

53. Fernando, I.P.S.; Sanjeewa, K.K.A.; Kim, H.S.; Wang, L.; Lee, W.W.; Jeon, Y.J. Apoptotic and antiproliferative properties of 3beta-hydroxy-Delta5-steroidal congeners from a partially purified column fraction of Dendronephthya gigantea against HL-60 and MCF-7 cancer cells. J. Appl. Toxicol. 2018, 38, 527-536. [CrossRef] [PubMed]

54. Jayawardena, T.U.; Lee, W.W.; Fernando, I.P.S.; Sanjeewa, K.K.A.; Wang, L.; Lee, T.G.; Park, Y.J.; Ko, C.-I.; Jeon, Y.-J. Antiproliferative and apoptosis-inducing potential of $3 \beta$-hydroxy- $\Delta 5$-steroidal congeners purified from the soft coral Dendronephthya putteri. J. Ocean. Limnol. 2018, 37, 1382-1392. [CrossRef]

55. Jayawardena, T.U.; Kim, H.-S.; Sanjeewa, K.K.A.; Kim, S.-Y.; Rho, J.-R.; Jee, Y.; Ahn, G.; Jeon, Y.-J. Sargassum horneri and isolated 6-hydroxy-4,4,7a-trimethyl-5,6,7,7a-tetrahydrobenzofuran-2(4H)-one (HTT); LPS-induced inflammation attenuation via suppressing NF- $\mathrm{B}, \mathrm{MAPK}$ and oxidative stress through Nrf2/HO-1 pathways in RAW 264.7 macrophages. Algal Res. 2019, 40, 101513. [CrossRef]

56. Fernando, I.P.S.; Lee, W.W.; Jayawardena, T.U.; Kang, M.-C.; Ann, Y.-S.; Ko, C.-I.; Park, Y.J.; Jeon, Y.-J. $3 \beta$-Hydroxy- $\Delta 5$-steroidal congeners from a column fraction of Dendronephthya puetteri attenuate LPS-induced inflammatory responses in RAW 264.7 macrophages and zebrafish embryo model. RSC Adv. 2018, 8, 18626-18634. [CrossRef]

57. Ko, J.Y.; Kim, E.A.; Lee, J.H.; Kang, M.C.; Lee, J.S.; Kim, J.S.; Jung, W.K.; Jeon, Y.J. Protective effect of aquacultured flounder fish-derived peptide against oxidative stress in zebrafish. Fish Shellfish Immunol. 2014, 36, 320-323. [CrossRef]

58. Kim, E.A.; Lee, S.H.; Ko, C.I.; Cha, S.H.; Kang, M.C.; Kang, S.M.; Ko, S.C.; Lee, W.W.; Ko, J.Y.; Lee, J.H.; et al. Protective effect of fucoidan against AAPH-induced oxidative stress in zebrafish model. Carbohydr. Polym. 2014, 102, 185-191. [CrossRef]

(C) 2020 by the authors. Licensee MDPI, Basel, Switzerland. This article is an open access article distributed under the terms and conditions of the Creative Commons Attribution (CC BY) license (http://creativecommons.org/licenses/by/4.0/). 